\title{
FES Training in Aging: interim results show statistically significant improvements in mobility and muscle fiber size
}

\author{
Helmut Kern (1,2), Stefan Loefler (2), Christian Hofer (2), Michael Vogelauer (1), \\ Samantha Burggraf (2), Martina Grim-Stieger (1), Jan Cvecka (3), Dusan Hamar (3), \\ Nejc Sarabon (4), Feliciano Protasi (5), Antonio Musarò (6), Marco Sandri (7), Katia \\ Rossini (8), Ugo Carraro (8), Sandra Zampieri $(2,8)$
}

(1) Dept. of Physical Medicine and Rehabilitation, Wilhelminenspital Wien, Austria; (2) Ludwig Boltzmann Institute of Electrical Stimulation and Physical Rehabilitation, Wien, Austria; (3) Faculty of Physical Education and Sport, Comenius University, Bratislava, Slovakia; (4) University of Primorska, Science and Research Centre, Institute for Kinesiological Research, Koper, Slovenia; (5) CeSI - Center for Research on Ageing \& DNI - Dept. Neuroscience and Imaging, University G. d'Annunzio of Chieti, Italy; (6) DAHFMO-Unit of Histology and Medical Embryology, IIM, Sapienza University of Rome, Italy; (7) Venetian Institute of Molecular Medicine, Dulbecco Telethon Institute, and Dept. of Biomedical Science, University of Padova, Italy; (8) Laboratory of Translational Myology, Dept. Biomedical Sciences, University of Padova, Italy

\begin{abstract}
Aging is a multifactorial process that is characterized by decline in muscle mass and performance. Several factors, including reduced exercise, poor nutrition and modified hormonal metabolism, are responsible for changes in the rates of protein synthesis and degradation that drive skeletal muscle mass reduction with a consequent decline of force generation and mobility functional performances. Seniors with normal life style were enrolled: two groups in Vienna $(n=32)$ and two groups in Bratislava: $(n=19)$. All subjects were healthy and declared not to have any specific physical/disease problems. The two Vienna groups of seniors exercised for 10 weeks with two different types of training (leg press at the hospital or home-based functional electrical stimulation, h-b FES). Demografic data (age, height and weight) were recorded before and after the training period and before and after the training period the patients were submitted to mobility functional analyses and muscle biopsies. The mobility functional analyses were: 1 . gait speed $(10 \mathrm{~m}$ test fastest speed, in $\mathrm{m} / \mathrm{s}) ; 2$. time which the subject needed to rise from a chair for five times (5x Chair-Rise, in s); 3. Timed -Up-GoTest, in s; 4. Stair-Test, in s; 5 . isometric measurement of quadriceps force (Torque/kg, in $\mathrm{Nm} / \mathrm{kg}$ ); and 6. Dynamic Balance in mm. Preliminary analyses of muscle biopsies from quadriceps in some of the Vienna and Bratislava patients present morphometric results consistent with their functional behaviors. The statistically significant improvements in functional testings here reported demonstrates the effectiveness of h-b FES, and strongly support h-b FES, as a safe home-based method to improve contractility and performances of ageing muscles.
\end{abstract}

Key Words: FES, exercise training, aging, functional analyses, mobility, muscle fiber size

European Journal Translational Myology - Basic Applied Myology 2012; 22 (1\&2):61-67

Aging is a multifactorial process that is influenced by genetic factors, nutrition, lifestyle and general health status. One of the most striking effects of ageing is a certain reduction of muscle mass that occurs in all individuals. This decrease in muscle is driven by several factors including reduced exercise [20].

During the last decade, we contributed to translational myology in rehabilitation by studying effects of physical exercise induced by Functional Electrical 


\section{Training by FES in Aging}

European Journal Translational Myology - Basic Applied Myology 2012; 22 (1\&2): 61-67

Stimulation (FES) in the special case of Spinal Cord Injury patients affected by complete injury of the Conus Cauda, a syndrome in which the denervated leg muscles are fully disconnected from the nervous system. The Cauda Equina Syndrome is characterized by bladder and intestines areflexia, legs flaccid paralysis and pelvic anesthesia. It is a "rare disease": incidence per year is 3.4 per million people, and prevalence 8.9 per 100.000 Italians [3,4]. Denervated human muscles become unexcitable with commercial electrical stimulators for innervated muscles and undergo ultrastructural disorganization within a few months from SCI, while severe atrophy with nuclear clumping, and fibro-fatty degeneration appear within 3 and 6 years, respectively $[3,9,12,16]$. To counteract these progressive changes a novel therapy concept for paraplegic patients with complete lower motor neuron denervation of the lower extremity was developed in Vienna: home-based functional electrical stimulation of long-term denervated muscles (h-b FES). New electrodes and stimulator have been designed to reverse severe atrophy by delivering high-intensity and long-duration impulses able to elicit contractions of denervated skeletal muscle fibers in absence of nerves $[8,13]$. At the same time, specific clinical assessments and training strategies were developed at the Wilhelminenspital Wien, Austria [13], based on sound evidence from animal experiments (rat) performed at the University of Padova, Italy [19] and the University of Liverpool, UK [1]. Light and electron microscopy of muscle biopsies were performed in Italy at the Universities of Padova and of Chieti, respectively. Main results [5,10,11] of a clinical study (EU Program RISE: Use of electrical stimulation to restore standing in paraplegics with long-term denervated degenerated muscles. Contract No: QLG5-CT-2001-02191) on patients which completed the 2-year h-b FES training are: 1. significant increase of muscle mass and of myofiber size, with striking improvements of the ultrastructural organization; 2. recovery of tetanic contractility with significant increase in muscle force output during electrical stimulation; 3. capacity to perform FES-assisted stand-up and stepping-in-place exercises. The study demonstrated that h-b FES of permanent denervated muscle is an effective home therapy that results in rescue of muscle mass, function and perfusion also in such a devastating muscle disease. Additional benefits, important for the patients, were the improved cosmetic appearance of the legs and the enhanced cushioning effect for seating.

We are now extending our research activities to application of h-b FES to the larger cohort of elderlies. In order to assess the effects of exercise on aging, we are comparing young [14] and senior male subjects either elderlies with a normal life stile or senior sportsmen (a peculiar group of subjects that performed life-long sport activities, with a mean age of 70 years) by functional analyses, and morphometry of light and electron microscopy, and molecular approaches on quadriceps muscle biopsies (manuscripts in preparation).

Here, instead, we report the interim results of a study in which seniors with normal life style are exercising for several weeks with two different types of training (leg press or electrical stimulation), the analyses being performed before and after the training period. The preliminary results of the functional testing here reported show the effectiveness of h-b FES, and strongly support h-b FES as a safe home-based method to improve contractility and performance of ageing musclesl.

\section{Materials and Methods}

Subjects enrolled in the study

All subjects recruited for the study were volunteers who received detailed information about the functional test protocols, about the trainings and muscle biopsies, and all signed an informed consent. Approval from the national committee for medical ethics was obtained at the beginning of the study (EK08-102-0608). Groups of seniors with normal life style were enrolled: two in Vienna and two in Bratislava. Tables 1 and Tables 2 show demography of the four groups. All subjects included were healthy and declared not to have any specific physical/disease issue.

Force measurement

An isometric measurement on a force chair (wise Technologies, Lubljana, Slovenia) was performed to assess the maximal isometric torque and rate of force development of the left and right knee extensors. The subjects were positioned with hip at $90^{\circ}$ flexion, the knee at $60^{\circ}$ flexion (full knee extension $=0$ ) and the arms crossed at the chest. The shank brace was positioned on the distal $1 / 3$ of the lower leg, two fingers above the malleolus lateralis and the trunk was fixed with a seat belt tightening system. Each subject was instructed to push alternating with one leg as fast as hard as possible against a shank support. In each case the maximal voluntary contraction (MVC) should be sustained for three seconds. All measurements were repeated three times for the right and left leg. The best value of each leg was taken for further analyses.

Functional Tests

A complete set of functional tests was designed and applied to each of the subjects belonging to the different groups. These tests included: time up and go test (TUGT) [15], 10m-walking test [17], short physical performance battery (SPPB)[7], and Dynamic Balance [18].

For the TUGT the subjects were asked to stand up from a standard chair, walk a distance of 3 meters as fast as possible, turn around, walk back to the chair and sit down again. The individuals used their usual footwear and no assistive walking device. Timing, using a stop watch (Track Pro, Conrad Electronics), began when the subjects started to leave the chair back 
Training by FES in Aging

European Journal Translational Myology - Basic Applied Myology 2012; 22 (1\&2): 61-67

Table 1 Demography of study subjects enrolled in Vienna

\begin{tabular}{lcccc} 
VIENNA & & $\begin{array}{c}\text { Legpress Group } \\
\mathrm{n}=16\end{array}$ & $\begin{array}{c}\text { Stimulation Group } \\
\mathrm{n}=16\end{array}$ & t test \\
\hline Age (years) & pre training & $74.93 \pm 5.48$ & $73.20 \pm 6.56$ & 0.956 \\
Height $(\mathrm{cm})$ & pre training & $170.84 \pm 9.22$ & $168.47 \pm 10.92$ & 0.780 \\
Weight $(\mathrm{kg})$ & pre training & $79.96 \pm 14.71$ & $80.18 \pm 19.32$ & 0.947 \\
\hline
\end{tabular}

Table 2 Demography of study subjects enrolled in Bratislava

\begin{tabular}{lcccc}
\multicolumn{1}{l}{ BRATISLAVA } & $\begin{array}{c}\text { Legpress Group } \\
\mathrm{n}=9\end{array}$ & $\begin{array}{c}\text { Stimulation Group } \\
\mathrm{n}=9\end{array}$ & $\mathrm{t}$ test \\
\hline Age (years) & pre training & $71.12 \pm 3.34$ & $70.41 \pm 3.74$ & 0.704 \\
Height $(\mathrm{cm})$ & pre training & $166.70 \pm 11.12$ & $168.22 \pm 5.63$ & 0.997 \\
Weight $(\mathrm{kg})$ & pre training & $71.40 \pm 14.46$ & $79.89 \pm 8.68$ & 0.634 \\
\hline
\end{tabular}

and ended when they were seated on the chair again [15].

For the $10 \mathrm{~m}$-walking test the subjects were asked to walk a distance of 10 -meter with their preferred speed (i.e. the self chosen normal speed of walking) and very fast speed (i.e. the fastest walking speed, but not running). Each speed was performed three times. Parameters of gait (average walking speed, average step length and average step cadence) in every 10meter walking trial were calculated using a combination of a standard stop watch (Track Pro, Conrad Electronics), counting the number of steps and subjective estimation of the remained part of the last step as described [17].

The SPPB used for this study evaluated the lower extremities function by using tests of gait speed $(2,4$ $\mathrm{m})$, standing balance and the time which the subject needed to rise from a chair for five times as quickest as possible with the arms folded across their chest [7].

The standing balance was evaluated with three standing position: the participants attempted to maintain the side-by-side, semi tandem, and tandem position for 10 seconds. For the body sway measurements the subject's task was to maintain three position with special foot placements during quiet stance of a force plate. Their hands were placed on their hips, the knees fully extended and their gaze was directed at a certain point in front of the body. The following foot placements were used: parallel stance with open eyes, semi-tandem stance with open and closed eyes. The subject performed each individual task with three trials, each lasting 30 seconds. The sequence of performing the balance tasks was randomized [18]. For the sway measurements the subjects stood on a force plate with their hands placed on their hips, the knees fully extended and their gaze directed at a display in front of the body. The subjects performed each task alternating with three trials, each lasting 30 seconds.

Analyses of human muscle biopsies

Needle muscle biopsies were harvested at enrollment and after exercise training through a small skin incision $(6 \mathrm{~mm})$ from the right and left vastus lateralis muscles of each patient as previously described [9]. The resulting specimens were then prepared either for light [16] or electron microscopy (EM)[3]. Light microscopy analyses were performed at the University of Padova (Italy). Morphometric analysis was performed using Scion Image for Windows version Beta 4.0.2 (2000 Scion Corporation). Tissue type distribution was determined using the Adobe Photoshop software (Adobe Systems Incorporated, San Jose, CA).

Ongoing ultrastructural analyses by EM at the University of Chieti (Italy) are as described in Boncompagni et al. [3]. Ongoing analyses of 


\section{Training by FES in Aging}

European Journal Translational Myology - Basic Applied Myology 2012; 22 (1\&2): 61-67

Table 3. Functional tests results before and after training of the subjects enrolled in Vienna

\begin{tabular}{|c|c|c|c|c|c|}
\hline VIENNA & \multicolumn{2}{|c|}{$\begin{array}{l}\text { Legpress Group } \\
\qquad \mathrm{n}=16\end{array}$} & \multicolumn{3}{|c|}{$\begin{array}{l}\text { Stimulation Group } \mathrm{t} \text { test } \\
\mathrm{n}=16\end{array}$} \\
\hline 10m test fastest speed $(\mathrm{m} / \mathrm{s})$ & pre training & $1.72 \pm 0.30$ & & $1.76 \pm 0.33$ & \\
\hline [more means faster $=$ better $]$ & post training & $1.88 \pm 0.36$ & $p=0.000$ & $1.91 \pm 0.38$ & $p=0.007$ \\
\hline 5x Chair-Rise (s) & pre training & $13.20 \pm 4.02$ & & $13.72 \pm 6.63$ & \\
\hline [less means faster $=$ better] & post training & $9.45 \pm 3.53$ & $p=0.000$ & $9.30 \pm 3.46$ & $p=0.013$ \\
\hline Timed -Up-Go-Test (s) & pre training & $7.42 \pm 1.79$ & & $7.61 \pm 1.99$ & \\
\hline [less means faster $=$ better $]$ & post training & $6.72 \pm 2.51$ & $p=0.049$ & $5.98 \pm 1.40$ & $p=0.000$ \\
\hline Stair-Test (s) & pre training & $11.76 \pm 2.50$ & & $12.15 \pm 4.02$ & \\
\hline [less means faster $=$ better] & post training & $9.77 \pm 3.07$ & $p=0.000$ & $9.43 \pm 2.90$ & $p=0.000$ \\
\hline Torque/Weight (Nm/kg) & pre training & $1.27 \pm 0.40$ & & $1.38 \pm 0.66$ & \\
\hline [more means stronger = better] & post training & $1.37 \pm 0.40$ & $p=0.094$ & $1.56 \pm 0.77$ & $p=0.014$ \\
\hline Dynamic Balance (mm) & pre training & $17.58 \pm 3.53$ & & $14.85 \pm 3.69$ & \\
\hline [less means more stable $=$ better & post training & $16.39 \pm 2.57$ & $p=0.018$ & $14.12 \pm 2.99$ & $p=0.077$ \\
\hline
\end{tabular}

Table 4. Functional tests results before and after training of the subjects enrolled in Bratislava

BRATISLAVA

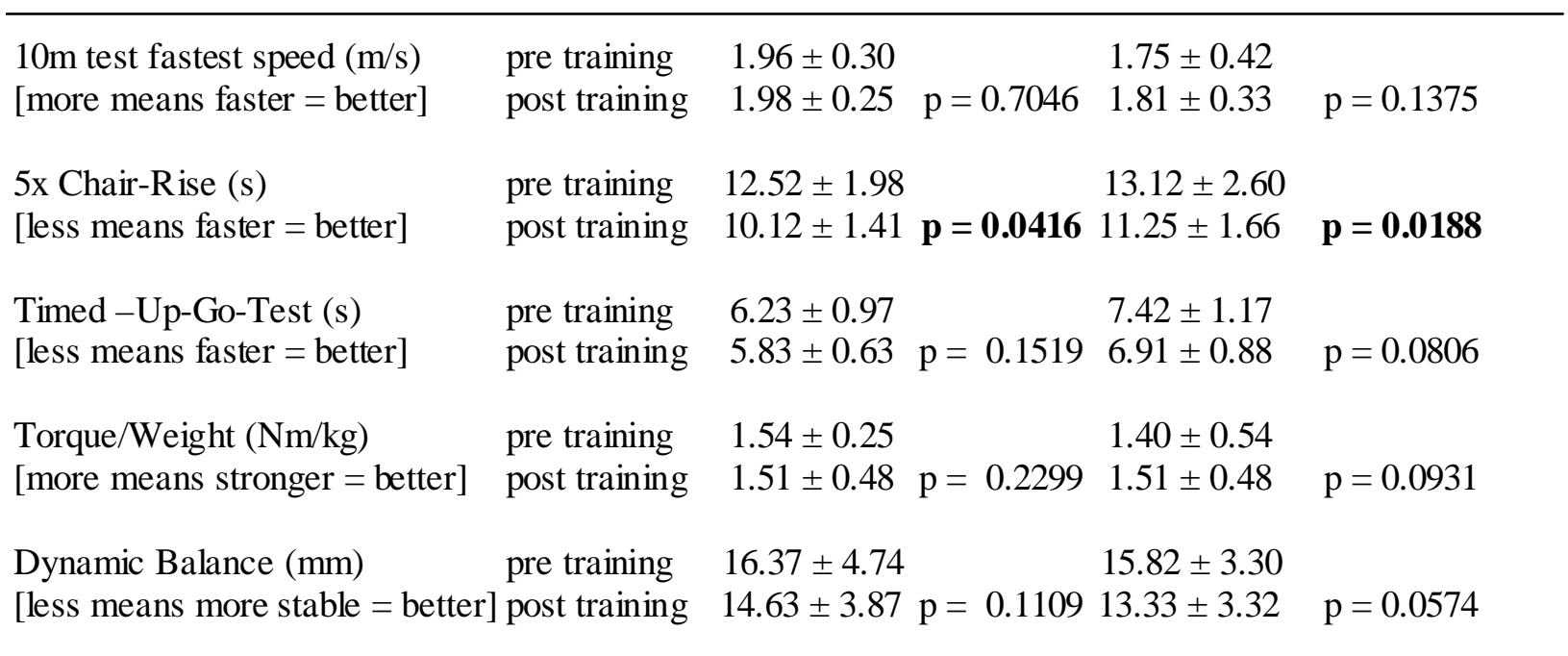

Legpress Group t test Stimulation Group $\quad$ t test

$$
\mathrm{n}=9 \quad \mathrm{n}=9
$$

atrophy/hypertrophy cell signaling in muscle biopsies are essentially as described in [14].

Exercise trainings

The four groups of patients were submitted to physical training either by home-based (in Vienna) or surveyed (in Bratislava) Functional Electrical Stimulation (aSl "Schwellstrom" programme, Stimulette rx, Dr.
Schufried Medizintechnik, Vienna) for either 10 (in Vienna) or 8 (in Bratislava) weeks of training. Two additional groups were submitted to vibration legpress exercise (custom made linear motor driven legpress [14]) for either 10 (in Vienna) or 8 (in Bratislava) weeks of training. 
Table 5. Myofibers mean diameter in biopsies from subjects enrolled in Vienna or Bratislava

\section{Electrical stimulation Group \\ (mean, $\mu \mathrm{m} \pm \mathrm{SD}$ )t test}

$\begin{array}{lrl}\text { VIENNA }(\mathrm{n}=1) & \\ \text { pre training } & 53.07 \pm 19.04 & \\ \text { post training } & 58.75 \pm 21.78 & \mathbf{p}=\mathbf{0 . 0 0 0 0}\end{array}$

$\begin{array}{lll}\text { BRATISLAVA }(\mathrm{n}=4) & \\ \text { pre training } & 51.94 \pm 16.27 & \\ \text { post training } & 56.67 \pm 14.45 & \mathbf{p}=\mathbf{0 . 0 0 0 0} \\ \text { pre training } & 54.59 \pm 16.05 & \\ \text { post training } & 56.03 \pm 16.00 & \mathbf{p}=\mathbf{0 . 0 0 0 0} \\ \text { pre training } & 46.32 \pm 12.59 & \\ \text { post training } & 49.44 \pm 13.40 & \mathbf{p}=\mathbf{0 . 0 0 0 0} \\ \text { pre training } & 50.73 \pm 11.84 & \\ \text { post training } & 51.46 \pm 11.19 & \mathrm{p}=0.3496\end{array}$

\section{Legpress Group}

(mean. $\mu \mathrm{m} \pm \mathrm{SD}$ )t test

VIENNA $(\mathrm{n}=1)$

pre training $\quad 46.43 \pm 12.73$

post training $\quad 57.24 \pm 15.59$

$\mathbf{p}=\mathbf{0 . 0 0 0 0}$

\begin{tabular}{|c|c|c|}
\hline \\
\hline & & pre training $\quad 53.35 \pm$ \\
\hline $\begin{array}{l}\text { re training } \\
\text { ost training } \\
\text { re training } \\
\text { ost training } \\
\text { re training } \\
\text { ost training }\end{array}$ & \multirow{2}{*}{$\begin{array}{ll}\text { st training } & 46.13 \pm 13.70 \\
\text { e training } & 46.27 \pm 11.60\end{array}$} & \multirow[t]{2}{*}{$p=0.0000$} \\
\hline \multirow{2}{*}{$\begin{array}{l}\text { pre training } \\
\text { post training }\end{array}$} & & \\
\hline & $63.27 \pm 16.85$ & \multirow[t]{2}{*}{$\mathrm{p}=\mathbf{0 . 0 0 0 0}$} \\
\hline \multirow{2}{*}{$\begin{array}{l}\text { pre training } \\
\text { post training }\end{array}$} & $62.53 \pm 13.76$ & \\
\hline & $61.86 \pm 16.34$ & $\mathrm{p}=0.5062$ \\
\hline
\end{tabular}

\section{Results}

The groups (legpress or FES) of aged subjects trained either in Vienna or in Bratislava have the expected non significant differences in age, height and weight before training (Table 1 and Table 2).

However, the subjects significantly differ in their ability to perform several functional mobility tests. The $10 \mathrm{~m}$ test fastest speed, $5 \mathrm{x}$ Chair-Rise, Timed-Up-Go-Test, Stair-Test, Dynamic Balance, and Torque/Weight posttraining performances are better or much better than those recorded in the pre-training tests (Table 3 and Table 4). Please note that in some tests the improvements are described by lesser values of time spent in performing a functional task. Maximal isometric torque was measured as a marker of muscle strength. The force generated by these seniors after the 10 (in Vienna) or 8 (in Bratislava) weeks of training was significantly higher compared to before training results. In the Vienna groups, the only clinically relevant exceptions are the lack of improvements in the Dynamic Balance Test of the FES trained group, and



Fig 1 Preliminary results of the ongoing myofiber morphometry show results consistent with the functional evidence (Tables 3 and 4). In comparison to pretraining (left panels), the post-training muscle biopsies (right panels) show an increase in muscle fiber diameter in the FES and legpress patients.

the Torque/Weight Test of the legpress trained groups (Table 3 andTable 4). The patients trained in Bratislava show statistically significant improvements in $5 \mathrm{x}$ Chair-Rise Test. The other functional tests show no significant improvements, but in these patients' groups the number of subjects is lower than those of Vienna. It must be also stressed that they are exercised for 8 weeks, i.e. a $20 \%$ percent less training time than in Vienna.

Ongoing analyses of light microscopy morphometry in the first exercised patients show data consistent with the improved functional results. In comparison to before training, the post-training results show increased mean muscle fiber diameters in muscle biopsies (Table 5 and Figure 1).

\section{Discussion}

Aging is associated with a variety of physical problems, musculoskeletal tissues become less functional, bone is more fragile, cartilage and ligaments have reduced elasticity, fat redistributes. One of the most striking effects of aging is a reduction of muscle mass that occurs more or less in all individuals. Muscle atrophy in aging is consequent to both the reduction of the total number of muscle fibers and the atrophy of the remaining ones [6]. This reduction is driven by several factors including reduced exercise [20]. In older people muscle weakness of the lower extremities, is responsible for having difficulty in rising up from a seated position and for the reduction in balance and mobility capabilities, which results in frequent falls, bone fractures, physical disabilities and progressive loss of independence [21]. 


\section{Training by FES in Aging}

European Journal Translational Myology - Basic Applied Myology 2012; 22 (1\&2): 61-67

We have here reported interim results of a study in which groups of 70 years old patients, mainly man with normal life-style and absence of incapacitating diseases, were submitted to physical training either by home-based (in Vienna) or surveyed (in Bratislava) Functional Electrical Stimulation for either 10 (in Vienna) or 8 (in Bratislava) weeks of training. Two additional groups were submitted to legpress exercise for either 10 (in Vienna) or 8 (in Bratislava) weeks of training. As shown in Tables 1 and 2 the demographic characteristics of the four patient groups do not present significant differences.

On the other hand, the two Vienna groups submitted to either h-b FES or Legpress for 10 weeks show increased functional performances, with two exceptions. The Dynamic balance test in h-b FES groups show improvements, but not yet statistically significant. The Torque/Weight results in the legpress group also show no statistically significant improvement. The shorter time of exercised training and the smaller groups of Bratislava patients reached statistically significant improvements only in the $5 x$ Chair-Rise tests in both training types. Interestingly, the FES group of Bratislava is also not far from significant improvements in Dynamic Balance testing. Despite low numerosity, preliminary analyses of muscle biopsies of quadriceps muscle from small numbers of Vienna and Bratislava patients present morphometric results coherent with the functional behaviors of the patients (Table 5), promising that ultrastructural changes analysed by electron microscopy (results not shown) may provide the structural basis to explain the functional improvements induced by h-b FES. Ongoing molecular analyses will hopefully add to the structural evidence, information on anabolic factors, such as expression of different isoforms of IGF-1, and catabolic factors (IL-6 and oxidative stress) that may modulate muscle mass and function. Preliminary data suggests a unique profile of actions for IGF-1Ea and IGF-1Eb isoforms. Protein synthesis and protein degradation are coordinately regulated by pathways that are influenced by mechanical stress, physical activity, availability of nutrients and growth factors.

Analyses of the pathways that control muscle mass in aging and disuse, with particular emphasis on ubiquitin-proteasome and autophagy-lysosome systems may provide potential further information on the activated mechanisms of exercise-induced muscle growth, adding to the knowledge on muscle wasting in aging and its complicances.

The interim data here reported, though preliminary, in particular the statistical significance of the functional improvements in the Vienna groups allows two important conclusions: first that longer periods of training in the range of 8 to 10 weeks made a difference in overall functional results (longer is better); second, they strongly support home-based FES, as a safe method to improve contractility and performances of aging muscles.

\section{Acknowledgements}

The expert technical assistance of Valerio Gobbo is gratefully acknowledged. This study was in part supported by: the European regional development fund (ERDF, Interreg IVa Project N_00033 MOBIL); the research funds to the Ludwig Boltzmann Institute for Electrostimulation and Physical Rehabilitation (Wilhelminenspital, Wien, Austria); Italian MIUR and Telethon Grant GGP08153 funds to Prof. F. Protasi, CeSI, Chieti, Italy supported EM analyses; institutional funds to the Translational Myology Lab, Department of Biomedical Science, University of Padova, Italy and the Italian MIUR funds (RISE2-Italy) to Prof. Carraro; and the 7FP Myoage (Grant Agreement Number 223576).

\section{Corresponding Author}

Sandra Zampieri, Ludwig Boltzmann Institute of Electrical Stimulation and Physical Rehabilitation at the Dept. of Physical Medicine and Rehabilitation, Wilhelminenspital Wien, Austria; and Laboratory of Translational Myology of the Dept. of Biomedical Sciences, University of Padua, Italy. E-mail: sanzamp@unipd.it .

\section{References}

[1] Ashley Z, Salmons S, Boncompagni S, Protasi F, Russold M, Lanmuller H, Mayr W, Sutherland H, Jarvis JC. Effects of chronic electrical stimulation on long-term denervated muscles of the rabbit hind limb. J Muscle Res Cell Motil. 2007;28:203217. Epub 2007 Sep 29.

[2] Bizzarini E, Zampa A, Malisan C, Pinzini C, Di Benedetto P, Kern H, Adami N, Carraro U. Epidemiology and clinical management of ConusCauda Syndrome and flaccid paraplegia in Friuli Venezia Giulia: Data of the Spinal Unit of Udine. Basic Appl Myol 2009;19:163-167.

[3] Boncompagni S, Kern H, Rossini K, Hofer C, Mayr W, Carraro U, Protasi F. Structural differentiation of skeletal muscle fibers in the absence of innervation in humans. Proc Natl Acad Sci U S A. 2007;104:19339-19344.

[4] Borghero A, Duca R, Leucci M, Cortese F. Epidemyology of Cauda Equina syndrome in the Spinal Unit of the Vicenza General Hospital. Basic Appl Myol 2009;19:173-174.

[5] Gargiulo P, Reynisson PJ, Helgason B, Kern H, Mayr W, Ingvarsson P, Helgason T, Carraro U. Muscle, tendons, and bone: structural changes during denervation and FES treatment. Neurol Res. 2011; 33:750-758.

[6] Goodpaster BH, Carlson CL, Visser M, Kelley DE, Scherzinger A, Harris TB, Stamm E, Newman AB. Attenuation of skeletal muscle and 


\section{Training by FES in Aging}

European Journal Translational Myology - Basic Applied Myology 2012; 22 (1\&2): 61-67

strength in the elderly: The Health ABC Study. J Appl Physiol. 2001; 90: 2157-2165.

[7] Guralnik JM, Simonsick EM, Ferrucci L, Glynn RJ, Berkman LF, Blazer DG, Scherr PA, Wallace RB. A short physical performance battery assessing lower extremity function: association with self-reported disability and prediction of mortality and nursing home admission. J Gerontol. 1994 ; 49: M85-94.

[8] Hofer C, Mayr W, Stöhr H, Unger E, Kern H. A stimulator for functional activation of denervated muscles. Artif Organs 2002;26:276-279.

[9] Kern H, Boncompagni S, Rossini K, Mayr W, Fanò G, Zanin ME, Podhorska-Okolow M, Protasi F, Carraro U. Long-term denervation in humans causes degeneration of both contractile and excitation-contraction coupling apparatus that can be reversed by functional electrical stimulation (FES). A role for myofiber regeneration? J Neuropath Exp Neurol 2004;63:919-931.

[10] Kern H, Carraro U, Adami N, Biral D Hofer C, Forstner C, Mödlin M, Vogelauer M, Boncompagni S, Paolini C, Mayr W, Protasi F, Zampieri S. Home-based Functional Electrical Stimulation (h-b FES) recovers permanently denervated muscles in paraplegic patients with complete lower motor neuron lesion. Neurorehab Neur Rep 2010; 24: 709-721.

[11] Kern H, Carraro U, Adami N, Hofer C, Loefler S, Vogelauer M, Mayr W, Rupp R, Zampieri S. One year of home-based Functional Electrical Stimulation (FES) in complete lower motor neuron paraplegia: Recovery of tetanic contractility drives the structural improvements of denervated muscle. Neurol Res 2010; 32 (1) 5-12.

[12] Kern H, Carraro U, Biral D, Adami N, Zampieri S. Severely atrophic muscle fibers with nuclear clumps survive many years in permanently denervated human muscle. The Open Pathology Journal 2009; 3: 106-110.

[13] Kern H, Hofer C, Mayr W, Carraro U. European Project RISE: Partners, protocols, demography. Basic Appl Myol/ European Journal of Translational Myology 2009;19:211-216.
[14] Kern H, Pelosi L, Coletto L, Musarò A, Sandri M, Vogelauer M, Trimmel L, Cvecka J, Hamar D, Kovarik J, Löfler S, Sarabon N, Protasi F, Adami $\mathrm{N}$, Biral D, Zampieri S, Carraro U. Atrophy/hypertrophy cell signaling in muscles of young athletes trained with vibrationalproprioceptive stimulation. Neurol Res. 2011;33:998-1009.

[15] Podsiadlo D, Richardson S, The timed "Up \& Go": a test of basic functional mobility for frail elderly persons. J Am Geriatr Soc. 1991; 39: 142148.

[16] Rossini K, Zanin ME, Carraro U. To stage and quantify regenerative myogenesis in human longterm permanent denervated muscle. Basic Appl Myol 2002;12:277-286.

[17] Sarabon N, Loefler S, Fruhmann H, Burggraf S, Kern H. Reduction and technical simplification of testing protocol for walking based on repeatability analyses: An Interreg IVa pilot study. European Journal of Translational Myology-Based and Applied Myology 2010; 1: 181-86.

[18] Sarabon N, Rosker J, Loefler S, Kern H. Sensitivity of body sway parameters during quiet standing to manipulation of support surface size. Journal of Sport Science and Medicine 2010; 9: 431-438.

[19] Squecco R, Carraro U, Kern H, Pond A, Adami $\mathrm{N}$, Biral D, Vindigni $\mathrm{V}$, Boncompagni $\mathrm{S}$, Pietrangelo $T$, Bosco $G$, Fanò $G$, Marini $M$, Abruzzo PM, Germinario E, Danieli-Betto D, Protasi F, Francini F, Zampieri S. Despite lost contractility, a sub-population of rat muscle fibers maintains an assessable excitation-contraction coupling mechanism after long-standing denervation. J Neuropath Exp Neurol 2009;68:1256-1268.

[20] Thomas DR. Loss of skeletal muscle mass in aging: examining the relationship of starvation, sarcopenia and cachexia. Clin Nutrition 2007; 26: 389-99.

[21] Toraman A, Yildirim NU. The falling risk and physical fitness in older people. Arch Gerontol Geriatr. 2010; 51: 222-622. 